\title{
Analysis of the Development of Logistics Market in Beijing
}

\author{
Hongming Fu
}

\author{
School of Management, Wuhan University of Technology, China \\ 986009330@qq.com
}

\begin{abstract}
Logistics is an indispensable part of today's life, and its development is of great significance for social and economic development. Beijing, as the capital of China, is one of the four first-tier cities. The development characteristics of the logistics market have certain typical characteristics. This article has conducted an in-depth analysis of the status quo of the development of the Beijing logistics market, and the problems existing in the development of the Beijing logistics market. Combined with Beijing logistics market development plan, put forward the scientific planning and construction of Beijing logistics market system as the prerequisite, to the cultivation of professional talents as the center of gravity, relevant policy to develop the logistics industry, the logistics industry standard to ensure the train of thought to develop the logistics market in Beijing.
\end{abstract}

Keywords: Beijing; logistics market; development; investigation.

\section{北京地区物流市场发展调查分析}

\author{
富泓茗 \\ 武汉理工大学管理学院 \\ 986009330@qq.com
}

摘 要: 物流作为当今生活中不可或缺的部分, 其发展对于社会经济发展具有重要意义。北京 作为我国的首都, 是四大一线城市之一, 物流市场的发展特征具有一定的典型性, 本文对北 京物流市场发展的现状进行了深入的分析, 对北京物流市场发展过程中的存在的问题进行了 调查分析, 结合北京物流市场发展规划, 提出了以科学规划、建设北京物流市场体系为前提, 以专业人才的培养为重心, 以制定物流行业相关政策, 规范物流行业标准为保障的思路来发展 北京的物流市场。

关键词: 北京; 物流市场; 发展; 调查。

\section{1. 绪论}

\section{1 调查背景}

近年来, 物流市场的需求量逐渐增多, 物流行业的迅猛发展, 在经济上带来了前所未有的变化, 因此, 在 社会上受到了广泛的关注。由于中国物流行业处于发展的现阶段, 在其他发展中国家而言起步较晚, 但是 随着国民经济的飞速发展下, 在物流市场迅速发展的同时, 面临的问题也会相对明显。物流市场的结构不 完善，市场环境的变化、经济政策的约束、竞争激烈的情况下，制约着物流市场整体的规划和管理格局。

\section{2 调查意义}

对物流市场发展的调查, 尤其是北京地区的物流市场分析, 就是解决北京地区物流市场发展的系统进行全 面的研究和规划。现代化的物流体系, 加快整合系统和规模扩张, 推动其更好的经济发展, 使物流企业迅 速发展。在专业化和规范化的物流市场条件下, 制定完整的服务体制, 提高服务质量和经济管理水平, 为 北京地区的物流市场培养专业的物流人才, 加强物流组织管理, 推动北京地区物流行业的经济建设和市场 发展。 


\section{2. 北京市物流市场发展现状}

现代化的物流市场逐步成型，符合国内的市场需求。在物流市场的多样化格局下，复杂的物流经济体制给 物流经营带来更大的变化, 国内的竞争激烈争相不下, 全球化的经济发展, 促使国内物流市场向着专业化、 规范化、合理化的方向进行发展。第三方物流服务规模小, 反映了国内物流市场发展的整体水平不高, 在 第三方物流企业规模上，也与国外物流企业规模的差距较大。在交通运输和存储设施上，国内物流的基 础设施能力不足, 不能完全适应国内的市场经济发展的需求。现代化信息技术的能力水平较低, 物流管理 体制、技术手段的不完善, 导致了物流速度的降低, 物流成本的增多, 物流市场经济的落后。物流管理人 才的流失，但是物流市场发展速度迅速，导致无法得到完整的人才管理体系。

目前北京的物流运输、仓储的现代化水平较低, 物流中心和配送中心的建设及集装箱运输的发展还比较慢, 物流企业特别是第三方物流企业的数量和规模小, 发展缓慢, 服务水平不高。物流企业普遍存在投资规模 小, 没有配套的信息化系统, 市场开拓能力不足, 专业化操作程度低, 服务质量和功能不能满足各种用户 需求等情况。

北京地区的物流市场受经济、生产力、基础设施、市场化程度、信息化水平、需求等因素的影响, 物流市 场呈现东部发展快, 中西部发展慢, 城市物流相对发达, 农村物流滞后且水平低。物流企业、物流设施、 物流活动高度集中在交通、信息更为发达的大中城市。北京地区现时物流市场发展面临的问题主要有内忧 及外患, 外患者是四方八面的竞争对手, 广州、上海、深圳资历优厚的潜力, 而且有着独到的地理优势, 长远而言北京未必能够抵受得住他们的竞争。而在内忧方面, 北京则受制于系统信息化的水平、独到的现 代化物流理念和物流市场整体的规划。

\section{3. 北京物流市场发展存在的问题研究}

国内的物流市场的行业需求范围不断扩大, 物流市场的发展前景不断多样化, 在推动经济发展上起到了至 关重要的地位。但物流市场的竞争区域的扩大, 服务量的不断扩增, 要求也会随之严格, 因此, 对物流 市场发展的进一步分析调查尤其重要。

当前的国内物流理念和运作水平还处于初级阶段, 在社会经济发展的依赖下, 社会物流总额持续扩增, 导 致了经济上的不景气。国内物流市场依旧是按照传统的经济模式运作，在物流模式上的投资较大，但规模 收益不高, 造成了物流市场资源的浪费。由于缺乏专业的物流市场引导和目标规划, 加大了物流成本, 降 低了社会效益。国内物流市场发展关注力度不够, 物流配送和物流信息没有形成网络化格局, 企业之间 信息流通不畅, 没有统一的协调机制。物流市场目前仍然处于散乱的状态, 缺乏专业化格局体系, 缺少协 调发展的机制。现代化物流市场的统一化程度不够, 相关部门的整体整体协调能力薄弱, 受地区的限制产 生了资源的浪费和服务质量的不合格。国内的物流市场信息系统处于建设之中, 才有规范化的信息体制势 在必得。这与现代化物流发展的要求和发达国家相比, 北京地区物流市场的发展存在很大差距, 主要存在 的问题如以下几个方面:

3.1 物流市场缺乏系统的协调性

传统的物流市场计划经济体制, 带给物流市场系统的协调性带来一定的困难。物流市场系统的关键在于 物流系统化的管理, 在各大运输行业、各大运输领域的各个环节的协调管理十分复杂, 但对于物流市场的 发展有重大的意义。

北京地区的传统的物流功能单一, 物流服务功能单一, 无专用货运机场, 缺乏港口货船的水运, 以及公路、 铁路、航空各立门户、互不衔接, 严重影响了物流的运输效率, 增加了流通的阻碍, 增大了物流成本, 加 剧了北京市的物流运输力度。北京市物流市场内部缺乏现代化的标准统一组织管理, 导致了交通等方面的 堵塞, 加大了社会制度的管理力度, 影响了合理化、规范化的物流制度, 影响了北京物流活动的质量、效 率和效益的提高以及国际物流活动的通畅。

3.2 物流管理专业化人才缺失

现代化物流市场的发展不是需要传统意义上的运输、调配、服务人员, 而是熟悉物流服务、运输组织和管 理相关业务, 熟悉市场营销和网络信息技术以及物流信息开发维护等多方面的专业人才。而目前北京物流 人才的培养不完善, 传统的从业人员已无法适应现代物流发展的要求, 事物流研究的大学和专业研究机构 还很少, 企业层面的研究和投入更微乎其微, 人才供需矛盾突出。物流市场研究相对落后和物流专业人才 短缺, 是物流产业发展的巨大障碍。

3.3 物流市场标准化体系落后

在物流设施、设备、信息化等标准化方面的落后，物流市场体制的不完善、发展不成熟的劣势条件下，物 流市场的推广难以发展和前进，而且在北京市物流企业内部的制度管理信息化系统和技术手段的相对落 
后, 物流市场组织及信息化程度比较落后, 标准的信息化流通也比较闭塞, 没有目的性明确的物流管理规 范条例，使得物流市场行业的行为准则得不到规范统一管理。

\section{4. 北京物流市场发展对策分析}

4.1 逐步发展北京物流体系

北京作为我国的首都, 是我国一个拥有高度的现代化的城市, 也是全国的政治中心和文化中心。北北京 的任意一项服务的好坏都象征着我国的服务水平的高低，在物流市场方面同样是这样。

同样的北京作为我国的首都, 资源也是相对丰富的, 近几年, 北京地区的物流市场实现平稳较快地发展, 物流基础设施日益完善，社会物流规模迅速增长，运行效率不断提高。大部分的货物来源于外部城市，解 决了大宗货物的物流涌入问题, 促进区域物流和省市物流的协调发展。独有的区域节点与线路的有效衔接, 合理化的物流配送平台，提供了商业物流重要的支撑和保障。

我国的物流市场的发展时间还比较短, 并没有像国外一些发达国家一样系统的将物流的各个环节衔接起 来, 形成一个完整的体系。有了成熟的物流市场作为目标和方向之后, 经过一段时间的发展, 我国的物流 市场的体系化也会逐渐形成，形成我国独有的物流体系。

4.2 鼓励物流企业，引进专业人才

北京作为首都和国际化大都市, 拥有的资源也是相对比较丰富, 有大量的人才可以挖掘。在物流这个行业 来说, 大多数物流企业平均利润率较低的特点, 一方面合理加大对物流基地入驻物流企业的优惠政策, 鼓 励和扶持物流企业入驻, 重新调整与完善物流基地的评价指标; 另一方面则是需要及时引进物流的专业性 人才, 能够有效的满足北京地区的物流行业的需求上, 提高物流系统的高效运作和有效衔接, 创造新型的 物流需求。

4.3 制定相关政策，规范物流标准

在物流行业的标准规范化上, 首先需要政府制定一套规范的物流行业标准, 有了标准之后, 各个地区的物 流行业则会逐渐根据不同区域经济规划与物流市场系统规划, 积极适应物流标准。这有利于促进物流行业 的仓储及其运输的效率，提升物流运行效率。同时政府应加强对道路、港口、机场等基础设施的建设以及 综合物流信息系统建设, 合理有效地促进物流业的货物运输。政府还需要加大对物流业技术装备的投资力 度, 提供税收优惠等相关政策, 进一步整合有效资源, 进行宏观调控和市场调配。合理化完善与物流行业 相关的法律法规政策，为物流业的各项措施提供法律依据和保障。物流企业要积极扩大规模，加快产权制 度改革以及完善公司治理结构，提高专业化服务水平同时提高物流从业人员的专业服务素质。

\section{References}

[1]. Xu Hua. Analysis of the gap between China's modern logistics management and developed countries [D]. University of International Business and Economics, 2007.

[2]. Zhu Tingjun. Research on logistics management of SMEs [D]. Dalian Maritime University, 2012.

[3]. Fu Pujun. Research on Collaborative Logistics Management Based on Informatization in Supply Chain [D]. Beijing Forestry University, 2013.

[4]. Li Yin. Research on the Influence of Science and Technology Progress and Innovation on Modern Logistics Management [D]. Bohai University, 2014.

[5]. Ma Na, Yan Shaoqing. Xiong Fei. Discussion on the development of logistics service contract standardization [J]. Economic Research Guide, 2011

[6]. Yang Yang. Internet of Things Technology and the Development of Beijing Logistics Industry [J]. Journal of Beijing Economic Management College, 2011 